Research Article

\title{
Local anesthetic agents along with hyaluronidase for inguinal hernia block provides excellent analgesia: a double blind study
}

\author{
Asmita V. Chaudhari ${ }^{1}$, Vipul P. Chaudhari ${ }^{2}$
}

\begin{abstract}
${ }^{1}$ Department of Anesthesia and ${ }^{2}$ Department of Pharmacology, Gujarat Cancer Society Medical College, Ahmedabad-380025, Gujarat, India
\end{abstract}

Received: 8 June 2013

Accepted: 28 June 2013

*Correspondence to: Dr. Asmita V. Chaudhari, Email: asmivip@yahoo.co.in

(C) 2013 Chaudhari AV. This is an open-access article distributed under the terms of the Creative Commons Attribution License, which permits unrestricted use, distribution, and reproduction in any medium, provided the original work is properly cited.

\begin{abstract}
Background: Inguinal hernia block is cost effective, but fear of intra-operative pain may hinder its widespread use. It is unknown whether hyaluronidase along with local anesthetic agent provides good analgesia for hernia block. The aim was to evaluate the effectiveness of hyaluronidase along with local anesthetic agents for inguinal hernia block in patients undergoing inguinal hernioplasty.

Methods: 50 patients ASA grade I and II, age above 18 years, undergoing inguinal hernioplasty were randomized into two groups. Group A received inguinal hernia block with local anesthetic agents without hyaluronidase and Group B received inguinal hernia block with hyaluronidase and local anesthetic agents. Both groups received premedication 10 minutes before induction in the form of inj. Fentanyl, Midazolam, Ranitidine and Ondansetron

Results: In Group B, out of 25 patients only 4 patients required intraoperative analgesia while in group A 16 patients required intraoperative analgesia. Post operative pain was assessed for 24 hours using the pain rating scale. The mean duration of analgesia was significantly longer in group B $(16.16 \pm 6.8780 \mathrm{hrs})$ compared to group A $(7.32 \pm 2.5285 \mathrm{hrs})$; pain score was compared between the two groups. Group B had lower pain scores than group A which was statistically significant $(\mathrm{P}<0.05)$.

Conclusion: It concludes that hyaluronidase with local anesthetic agent for inguinal hernia block provides excellent intraoperative analgesia and also prolongs the post operative analgesia.
\end{abstract}

Keywords: Hyaluronidase, Inguinal hernia, Local anesthetic agent, Hernioplasty

\section{INTRODUCTION}

Inguinal hernia repair is one of the most commonly performed operation worldwide. ${ }^{1}$ Inguinal hernia block is primarily a technique of peripheral block for inguinal hernioplasty. Number of patients undergoing inguinal hernioplasty as a day care procedure is increasing: thus this block should be incorporated in most practices. Current evidence supports the use of local infiltration anesthesia as it has a fast recovery, less urinary morbidity and overall costs. ${ }^{2,3}$ However despite these advantages hernia block is rarely used, ${ }^{4,5}$ at some centers. ${ }^{6-8}$ One of the explanations to the infrequent use of hernia block may be intraoperative patients discomfort and pain, other reason being tradition and surgeon's preference. Spinal anesthesia is an easy option but complications like urinary retention, vomiting and hypotension are frequently encountered. ${ }^{9}$ Several studies have shown that hernioplasty under local infiltration provides the best clinical and economic benefits to the patients. ${ }^{10}$

Motor blockade is not required for inguinal hernioplasty. Therefore, lower concentration of intermediate to long acting local anesthetic agents can be selected like; $1 \%$ lidocaine, $0.25 \%$ bupivacaine or $0.2 \%$ ropivacaine. In order to improve intraoperative analgesia local anesthetic agents along with hyaluronidase are used for hernia block. This combination provides excellent intraoperative analgesia.

Hyaluronidase is an enzyme which reduces the viscosity of ground substance thus making the tissues more 
permeable to injected fluids. ${ }^{11}$ In this era ultrasonography guided illioinguinal nerve block is very popular for inguinal hernioplasty. Ultrasonography machine is very costly and not available at periphery level so effective blind hernia block in high risk patient makes life easy for anaesthetist.

\section{METHODS}

After obtaining informed consent, randomized, controlled, double blind, single centre study was conducted on 50 patients with ASA physical status 1-2, age 18 to 80 years, undergoing inguinal hernioplasty under inguinal hernia block. Patients with obstructed, irreducible, recurrent inguinal hernia and infection at the site of block were excluded from the study.

The patients were randomly allocated into two groups. Group A (control group) and group B (study group). In the operation theatre patients were connected to monitors; electrocardiogram, non invasive blood pressure and pulse oximeter. Baseline values were recorded. Both the groups received premedication 10 minutes before hernia block in the form of inj. Midazolam 0.02-0.05 $\mathrm{mg} / \mathrm{kg}$, inj. Fentanyl 1-2 $\mu \mathrm{g} / \mathrm{kg}$, inj. Ranitidine $50 \mathrm{mg}$ and inj. Ondansetron $4 \mathrm{mg}$.

Inguinal hernias block technique:

- At a point $2 \mathrm{~cm}$ (two finger's breath) medial to the anterior superior iliac spine $23 \mathrm{G} 50 \mathrm{~mm}$ short beveled needle perpendicular to the skin was inserted.

- A pop was felt as a needle passed through the aponurosis of external oblique muscle; $8 \mathrm{ml}$ solution was injected blocking the iliohypogastric nerve.

- $8 \mathrm{ml}$ fluid was injected between the internal oblique muscle and the transverse abdominis to block the ilioinguinal nerve by redirecting the needle deeper to internal oblique muscle.

- Further fanwise subcutaneous infiltration superficial to the aponurosis blocked the cutaneous supply from the lower intercostals and subcostal nerves.

- After palpating deep inguinal ring, needle was inserted into the inguinal canal injecting $5 \mathrm{ml}$ to block the genital branch of the genitofemoral nerve.

- Subcutaneous infiltration at the medial end of incision or fan wise from the pubic tubercal blocks contralateral innervations.

- Local infiltration at the site of skin incision.

Group-A (Control): Inj. Xylocaine (20 Ml-2\%), Inj. Bupivacaine (20 Ml-0.5\%).

Inj NS (10 ml)
Group-B (Study): Inj. Xylocaine (20 Ml-2\%), Inj. Bupivacaine (20 Ml-0.5\%).

Inj. Hyaluronidase (1500 IU), Inj. NS (10 ml)

The patients were assessed for 24 hours post-operatively. Post operative assessment was done by sister in the post anaesthesia care unit (PACU). Physiological measures like heart rate and blood pressure were assessed for two hours in PACU. Pain score was assessed using the pain rating scale (Table 1). The severity of the pain was classified using the total pain rating score as given here with:

Table 1: Pain rating scale.

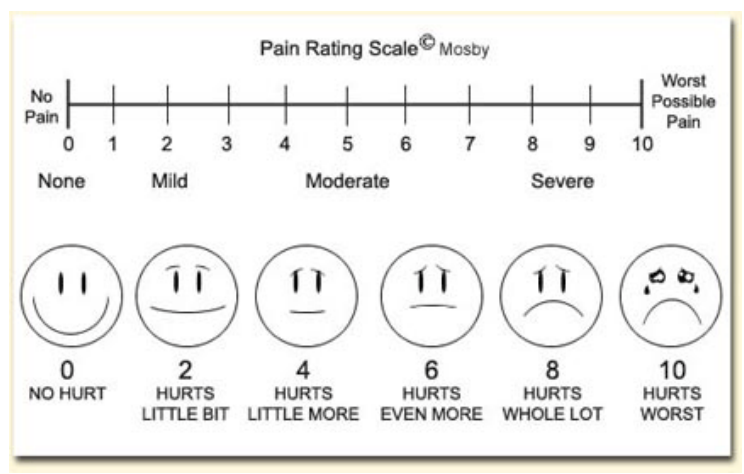

$0=$ no pain

$1-3=$ mild pain

4-7= moderate pain

$8-10=$ severe pain

The heart rate and blood pressure were measured at 0.5 , $1,1.5,2$ hours post operatively. Assessment of pain by pain rating scale was done at $0,1,2,6,12$ and 24 hours post operatively.

The necessity for rescue medicine was decided by the pain scale. Rescue medication was administered when the pain score was $>4$. Inj. Tramadol $100 \mathrm{mg}$ or Inj. Dynapar $75 \mathrm{mg}$ intravenous in $100 \mathrm{ml}$ normal saline infusion was used as rescue medicine.

In the PACU, patients were also monitored for adverse effects like; rashes, itching, vomiting, and convulsion.

\section{RESULTS}

Analysis of patients revealed no difference in demographic characteristics of the two groups (Table 2).

The mean age of the patients in the two groups was almost similar. Group A patients had a mean age of 56.84 years and group B had a mean age of 56.48 years. There 
was no significant difference in term of weight and duration of surgery.

Table 2: Demographic characteristics of two groups.

\begin{tabular}{|lll|}
\hline Variable & $\begin{array}{l}\text { Group A } \\
\text { (bupivacaine } \\
\text { and xylocaine) }\end{array}$ & $\begin{array}{l}\text { Group B } \\
\text { (bupivacaine, } \\
\text { xylocaine with } \\
\text { hyaluronidase) }\end{array}$ \\
\hline $\begin{array}{l}\text { Number of } \\
\text { patients }\end{array}$ & 25 & 25 \\
\hline Age (years) & 56.84 & 56.48 \\
\hline Sex & Male & Male \\
\hline $\begin{array}{l}\text { Duration of } \\
\text { surgery (hours) }\end{array}$ & 1.8 & 1.76 \\
\hline
\end{tabular}

The pain score was assessed using the pain rating scale and the two groups were compared using chi square test. There was significant difference between the two groups from two hours to six hours postoperatively with $\mathrm{p}$ value $<0.05$ (Table 3).

Table 3: Pain score at 2 hours and 6 hours postoperatively in both groups.

\begin{tabular}{|lll|}
\hline $\begin{array}{l}\text { Pain score } \\
\text { at 2 hours }\end{array}$ & $\begin{array}{l}\mathbf{0 - 3} \text { (no pain } \\
\text { or mild pain) } \\
\text { n (\%) }\end{array}$ & $\begin{array}{l}\text { 4-10 (Moderate } \\
\text { to severe pain) } \\
\text { n (\%) }\end{array}$ \\
\hline Group A & $9(36)$ & $16(64)$ \\
\hline Group B & $21(84)$ & $4(16)$ \\
\hline Pain score at 6 hours & \\
\hline Group A & $8(32)$ & $17(68)$ \\
\hline Group B & $19(76)$ & $6(24)$ \\
\hline
\end{tabular}

At 2 hours postoperatively, 16 patients (64\%) in group A had moderate to severe pain while only 4 patients $(16 \%)$ in group B had moderate to severe pain and the difference was statistically significant; $p$ value of 0.001 .

At 6 hours postoperatively, 17 patients $(68 \%)$ in group A and 6 patients $(24 \%)$ in group B had moderate to severe pain and the difference was statistically significant; $p$ value of 0.045 .

\section{DISCUSSION}

The prevalence of inguinal hernia is high in old and middle age. Most of the elderly patients having inguinal hernia also have concomitant disease (cardiac, pulmonary and diabetics) that increase the anaesthesia risk. ${ }^{12}$ cardiovascular, pulmonary and urinary complications can occur after inguinal hernioplasty, especially when the procedure is performed under general or spinal anaesthesia. On the other hand patients operated under hernia block do not generally have serious intra or post operative complications. ${ }^{13}$ Several retrospective and randomized control trials have shown that local anaesthesia (hernia block) provide the best clinical and economical benefits to patients. ${ }^{14-16}$ In spite of all these benefits, the use of inguinal hernia block has not been established among anaesthetists and surgeons on a wide scale. In this study, we assessed the safety and benefits of inguinal hernia blocks with local anesthetic agent along with hyaluronidase.

In our study, no patients developed anaphylaxis or local reaction. In this era, USG guided illioinguinal nerve block is very popular for inguinal hernioplasty. Ultrasonography machine for nerve block is very costly and not available at periphery level hence successful blind hernia block particularly in high risk patients may reduces morbidity and mortality.

Inguinal hernia block encourages early mobilization and early discharge from hospital. Hence it reduces hospital burden and cost effective, too. Inguinal hernia block is safe and convenient with less hypotension and urinary retention as compare to spinal anaesthesia. ${ }^{17}$

Patients may have fear of hernia block so preoperative counselling is required during pre anaesthesia check up. Premedication in the form of midazolam and fentanyl 10 minutes prior to hernia block makes the patients comfortable.

Our study showed that additional hyaluronidase along with local anesthetic agent for inguinal hernia block makes the onset of analgesia fast and prolongs post operative analgesia. ${ }^{18}$ In our study, only 4 patients in group B required intraoperative analgesia whereas 16 patients in group A required intraoperative analgesia. Callese $^{19}$ also proved in his study that local anesthesia facilitates the faster mobilization and early discharge from hospital than the other anaesthetic techniques.

Post operative pain was assessed for 24 hours using the pain rating scale; the mean duration of analgesia was significantly longer in group B $(16.16 \pm 6.87$ hours $)$ compare to group A $(7.32 \pm 2.52$ hours); pain rating scale was compared between the two groups shows lower pain scales in group B at 2 and 6 hours post operatively which was statistically significant $(\mathrm{p}<0.05)$.

Incidence of post operative nausea, vomiting and hypotension was negligible in our study and this is in line with other studies. $^{20,21}$

Combined ilioinguinal blockade and local infiltration anaesthesia is recommended for groin hernia repair to reduce intra- operative pain. ${ }^{22}$

\section{CONCLUSION}

Hernia block is recommended for day care inguinal hernioplasty as safe and effective technique. It is cost 
effective and reduces hospital burden, too. Addition of hyaluronidase along with local anesthetic agents provide excellent analgesia and prolong post-operative analgesia. Hernia block is a procedure of choice in elderly patients especially those with associated co-morbid condition.

\section{Funding: None}

Conflict of Interest: None declared

Ethical approval: The study was approved by the

Institutional Ethics Committee

\section{REFERENCES}

1. Baskerville PA, Jarrett PE. Day case inguinal hernia repair under local anaesthesia. Ann R Coll Surg Engl 1983;65:224-5.

2. Kehlet H, White PF. Optimizing anesthesia for inguinal herniorrphaphy: General, regional or local? Anesth Analg 2001; 93: 1367-9.

3. Nordin P, Zetterstro “MH, Gunnarsson U, Nilsson E. Local, Regional or general anaesthesia in groin hernia repair: multicenter Randomized trial. Lancet 2003;362:853-8.

4. Kark AE, Kurzer MN, Belsham PA. Three thousand one hundred and seventy-five primary inguinal hernia repairs: advantages of Ambulatory open mesh repair using local anesthesia. J Am Coll Surg 1998;186:447-55.

5. Bay-Nielsen M, Kehlet H, Strand L, et al. Quality assessment of 26, 304 herniorrhaphies in Denmark: a prospective nationwide Study. Lancet 2001;358:1124-8.

6. Glassow F. Short-stay surgeries (Shouldice technique) for repair of inguinal hernia. Ann R Coll Surg Engl 1976;58:133-9.

7. Amid PK, Shulman AG, Lichtenstein IL. Local anesthesia for inguinal hernia repair step-by-step procedure. Ann Surg 1994;220:735-7.

8. Callesen T, Bech K, Kehlet H. One-thousand consecutive inguinal Hernia repairs under unmonitored local anesthesia. Anesth Analg 2001;93:1373-6.

9. O'Dower PJ, Serpell MG, Millar K, Paterson C, Young D, Hair A, Courtney CA, et al. Local or general anaesthesia for open hernia repair: a randomized trial. Ann Surg 2003;237:574-9.

10. Callesen T, Bech K, Kehlet H. The feasibility, safety and cost of infiltration anaesthesia for hernia repair. Hvidovre Hospital Hernia Group. Anaesthesia 1998;53:31-5.

11. Dempsey GA, Barrett PJ, Kirby IJ. Hyaluronidase and peribulbar block. $\mathrm{Br}$ J Anaesth 1997 Jun;78(6):671-4.

12. Gianetta E. DeCian F, Cuneo S, Friendman D, Vitale B, Marinari G, et al. Hernia repair in elderly patients. Br J Surg 1997; 84: 983-5.

13. Young DV. Comparison of local, spinal and general anaesthesia for inguinal herniorrhaphy. Am J Surg 1987; 153:560-3.

14. Gonullu NN, Cubukcu A, Alponat A. Comparison of local and general anaesthesia in tension free (Lichtenstein) hernioplasty: a prospective randomized trial. Hernia 2002;6:29-32.

15. Ozgun H, Kurt MN, Kurt I, Cevikel MH. Comparison of local, spinal and general anaesthesia for inguinal herniorraphy. Eur J Surg 2002;168:4559.

16. Nordin P, Zetterstrom H, Gunnarsson U, Nilsson E. Local regional or general anaesthesia in groin hernia repairs; multicentre randomized trial. Lancet 2003;362:853-7.

17. Abdul Razaque Shaikh, Abdul Mannan Rao, Ambreen Muneer. Inguinal mesh hernioplasty under local anaesthesia. JPMA 2012;62:566-9.

18. Van Veen RN, Mahabier C, Dawson I, Hop WC, Kok NF, Lange JF, et al. Spinal or local anaesthesia in lichtenstein hernia repair: a randomised controlled trial. Ann Surg 2008;247:428-33.

19. Callese T, Inguinal hernia repair: anaesthesia, pain and convalescence. Dan Med Bull 2003;50:203-18.

20. Subramaiam P, Leslie J, Gourlay C, Clezy JK. Inguinal hernia repair: a comparison between local \& general anaesthesia. Aust NZ J Surg 1998;68:799-800.

21. Callesen $\mathrm{T}$, Bech K, Kehlet H. One thousand consecutive inguinal hernia Repairs under unmonitored local anaesthesia. Anesth Analg 2001;93:1373-6.

22. Andersen FH, Nielsen K, Kehlet H. Combined ilioinguinal blockade and local infiltration anaesthesia for groin hernia repair- a double-blind randomized study. Br J Anaesth 2005;94(4):520-3.

doi:10.5455/2319-2003.ijbcp20130822

Cite this article as: Chaudhari AV, Chaudhari VP. Local anaesthetic agents along with hyaluronidase for inguinal hernia block provides excellent analgesia: a double blind study. Int $\mathrm{J}$ Basic Clin Pharmacol 2013;2:466-9. 